\title{
Climate zoning of the Burgundy winegrowing region
}

\author{
Catinca Gavrilescu ${ }^{1}$, Yves Richard ${ }^{1}$, Daniel Joly ${ }^{2}$, Benjamin Bois ${ }^{1,3}$ \\ ${ }^{1}$ CRC - UMR Biogeosciences, Université Bourgogne Franche-Comté / CNRS, 6 Bd Gabriel, 21000 Dijon, \\ France \\ gavrilescu_catinca@yahoo.com, yves.richard@u-bourgogne.fr
}

${ }^{2}$ Université de Bourgogne Franche-Comté, THEMA-CNRS, France daniel.joly@univ-fcomte.fr

${ }^{3}$ Institut Universitaire de la Vigne et du Vin, Université Bourgogne Franche-Comté, rue Claude Ladrey, 21000 Dijon, France

benjamin.bois@u-bourgogne.fr

\begin{abstract}
As one of the most emblematic wine regions of cool climate terroir viticulture, Burgundy is endowed with a set of very specific natural features suitable to the production of high quality wines, where climate is arguably one of the main factors to profoundly influence vine physiology/phenology and grape composition. These environmental nuances have led to a wide variety of styles in Pinot noir and Chardonnay wines that have been largely acknowledged and appreciated by the international market and vitivinicultural industry. However, individual grape varieties optimum quality is known to be closely related to well-defined climate and geographical ranges. Climate change and global warming latest trends make them more susceptible to undergo modifications in terms of berry ripening processes and advancements in harvest dates due to short-term and long-term spatiotemporal fluctuations in climate variability. The impact of air temperature on grapevine development and harvest outcomes has been widely documented by the scientific community, its influence translating as quality and quantity fluctuations in space ("terroir" effect) and time ("vintage" effect). Through this study we aim to assess the extent of these threats by means of modelling and spatializing the regional climate variations based on 5 agricultural climatic indices: the number of days with temperatures equal or greater than $35^{\circ} \mathrm{C}$ (heat stress), the number of days indicating a frost risk (equal or greater than $-1^{\circ} \mathrm{C}$ ), the midflowering, the mid-véraison and the theoretical grape maturity $(200 \mathrm{~g} / \mathrm{l}$ of sugar) occurrence dates. Mid-flowering, midvéraison as well as the theoretical grape maturity were estimated through the summation of temperatures over $10^{\circ} \mathrm{C}$ (starting $1^{\text {st }}$ of March) based on the GFV (Grapevine Flowering Véraison) linear phenological model and were calculated for the 2 prime varieties cultivated in Burgundy (Chardonnay and Pinot noir). Daily minimum and maximum temperatures issued from a network of 64 weather stations scattered throughout the main 9 wine production subregions of Burgundy were spatially interpolated on a grid with a $75 \mathrm{~m}$ resolution over a 41751 ha area (74556 pixels). Spatial interpolations were performed at a daily time step integrating various topographical features through a regression-kriging model for the 2011-2015 period. Daily grid minimum and maximum temperatures were further used to calculate the 5 agroclimatic indices for each of the years of the study period. The entirety of the 74556 pixels were later classified at regular intervals in 6 groups which were assigned to each of the three phenological stages: "very early", "early", "intermediate", "late", "very late" and "variable". The number of heat stress days as well as those presenting a frost risk were equally classified based on their occurrence as "very rare", "rare", "intermediate", "frequent" and "very frequent". The annual spatial structure of the individual classes was very similar due to temperature distribution being strongly governed by terrain features. We were able to identify observable differences between the north and the south subregions of Burgundy with a potential variation ranging from 7 to 15 days in terms of phenological and theoretical maturity occurrence dates. Côte de Nuits and Côte de Beaune vineyards indicate similar climate characteristics with early phenological timing ( $97 \%$ and $82 \%$ respectively of the area classified as "early") and little frost and heat risks. The number of days with a frost risk is a lot more elevated in the Côte Châtillonnaise and the Chablis subregions, while the number of heat stress days was larger in the subregions located in the south of Burgundy.
\end{abstract}




\section{Introduction}

Viticulture is highly depended on weather and climate conditions, particularly during the grapevine's growth cycle $[1,2]$. As a terroir component, climate has been observed to have the largest influence on both grape and wine quality, followed by cultivar and soil [3]. Climate variability of wine regions is strongly related to their location, each geography producing different types of climate and meteorological events that vary both in frequency and intensity [4]. Given its importance for the wine industry, a fine scale spatial structure analysis of climate is indispensable when trying to understand and describe the potential of wine regions [5]. To this end, multiple viticultural climate zoning studies have been carried out $[6,7,8]$ in view of comparing the world winegrowing regions' climate profiles $[9,10]$, as well as to describe more locally and accurately the climate typicity of each individual wine region $[11,12,13]$. Climate discrepancies between the world viticultural areas are mainly attributed to differences in thermal regimes $[2,14$, 15]. Temperature has been reported to have a determinant role in the grapevine's different developmental stages [16, $17,18]$ and the berries' maturity $[19,20,3]$.

Thermal fields fine scale spatial analysis and characterization requires the use of an integrated approach by including the topographic component [21], which has been shown to have a very strong influence on the spatial distribution of climate parameters [22, 23].

The present study aims at describing and comparing the climate features of several Burgundy wine subregions while analyzing their thermal subtleties at a fine scale resolution (75m). This was achieved through a regressionkriging interpolation of minimum and maximum daily temperatures relative to the different topographic parameters derived from a digital elevation model (DEM). Finally, a typology of the viticultural subregions was developed as a result of the classification made on the basis of agroclimatic indices calculated from daily interpolated temperatures.

\section{Data and methods}

\subsection{Area of study and land use data}

This study has been carried out across the Burgundy winegrowing region, located in the east-central part of
France. Burgundy's viticultural climate has oceanic and meridional influences [24, 25], which results in hot and dry periods during summer and rainy periods in winter [26]. The climate analysis was performed for the areas actually planted in grapevines and not for the entire extent of the appellations of origin (AOC), the later including the whole vineyard potential areas of Burgundy. The 9 following wine producing subregions were studied: Côte de Nuits and Hautes Côtes de Nuits, Côte de Beaune and Hautes Côtes de Beaune, Côte Châtillonnaise, Chablis, Côtes du Couchois, Côte Chalonnaise, Mâconnais (Figure 1a). The vineyard area delimitation used for this study was that of CORINE Land Cover 2012 (CLC) European land use database [27]. The polygons depicting the vineyard areas (represented in violet in Figure 1a) were identified and retrieved based on a unique code (221). The CLC database vineyard polygons cover an area of $31468 \mathrm{ha}$, whereas the institutional organisms (e.g. BIVB - Bureau Interprofessionnel des Vins de Bourgogne) declared in 2014 an area of only 29000 ha ( $8.5 \%$ overestimation). This spatial inaccuracy has a very limited impact on the proposed zoning and is probably due to the difficulty of entirely dissociating the non-vineyard (residential zones, vegetation, etc.) of the actual vineyard areas.

\subsection{Climate data and cross validation}

The observed climate data used for this study were retrieved from two sources: the CLIMEO (owned and managed by the Chambre Régionale d'Agriculture de Bourgogne-Franche Comté and the BIVB) and the MétéoFrance weather stations networks. Based on this data, two databases were compiled, one with the daily minimum (tn) and another with the daily maximum (tx) temperatures. This research was carried out for the 2011-2015 period and it analysed a total of 3652 daily tn and tx (1826 each) recovered from 64 distinct weather stations spread across our study area (Figure 1b). However, these databases are incomplete due to missing values which account for $17 \%$ of the total data (with $17.5 \%$ of th and $16.6 \%$ of tx missing). Missing data was unavoidable as it corresponds to stations that were installed either after the beginning date of this study or they were shut down during it. Nevertheless, missing values were later estimated by interpolation of the daily tn and tx. The temperatures were gridded at a $75 \mathrm{~m}$ resolution (pixel size of the DEM) across 

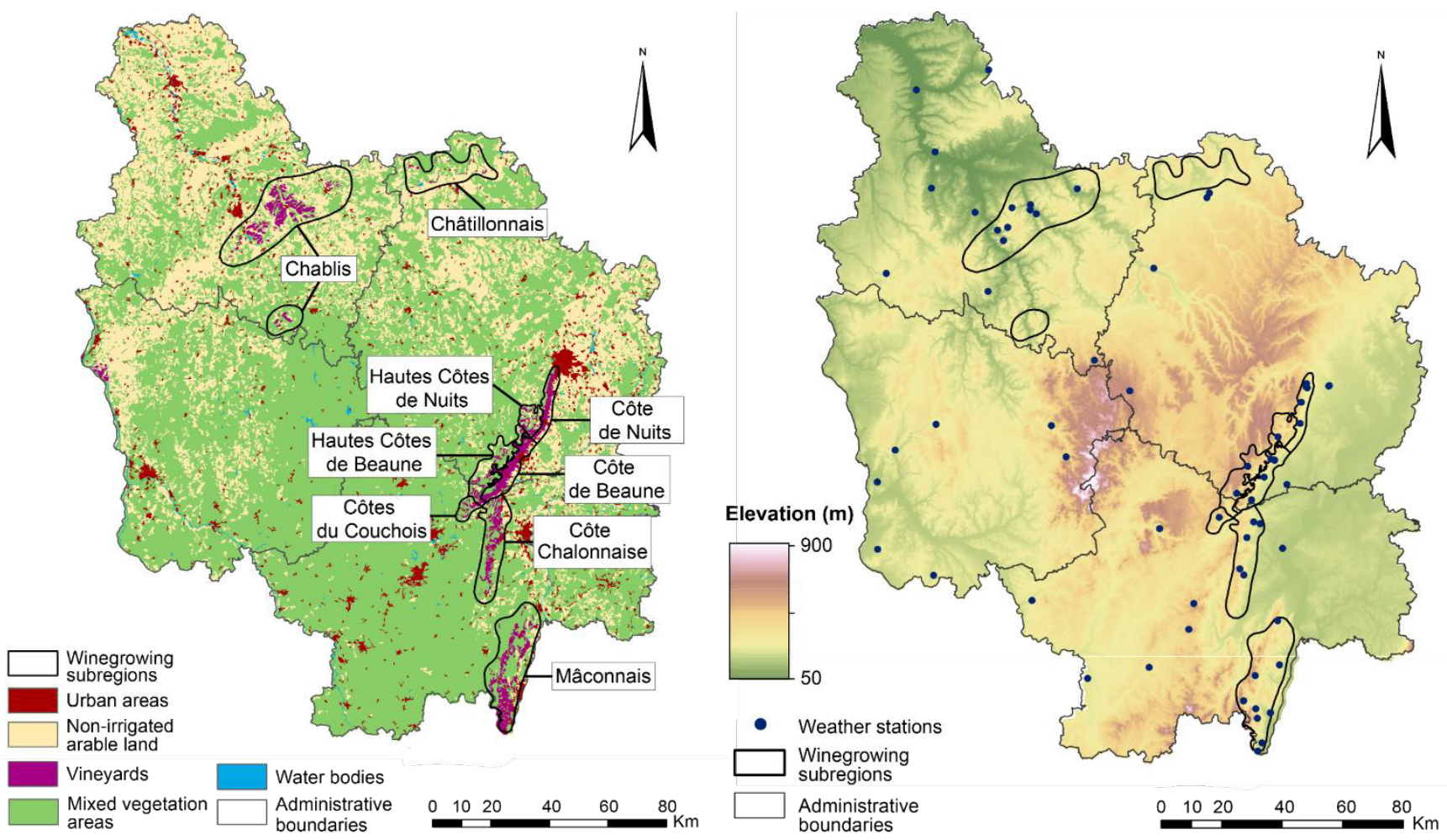

Figure 1: a) Geographical representation of Burgundy and its main land uses (CLC 2012). The vineyard area is represented in violet and it was separated in 9 subregions (thick black lines); b) Geographical location of the 64 weather stations.

the whole study area and were later extracted for the vineyard areas only by using the CLC vineyard polygons. The number of estimated pixels corresponding to the vineyards was of 74556 which account for an area of 41751 ha. The interpolation method applied was that of the regression-kriging [28, 29], which is divided in three steps: 1) establishing the correlation between a predictor (topographic parameters) and a predictant (tn and tx); 2) interpolating the regression residuals and 3) adding the interpolated residuals (2) to the prediction model (1). By following these steps, 3652 gridded daily temperatures were obtained (1826 for each) and cross validated using the LOOCV (Leave-one-out cross validation) method. Model performance was assessed for all stations as well as for those installed exclusively in the vineyard areas and we based it on three statistical indices: the $\mathrm{R}^{2}$ (determination coefficient), the RMSE (root mean square errors) and the EF (model efficiency).

$$
E F=1-\frac{\sum_{i=1}^{n}\left(P_{i}-O i\right)^{2}}{\sum_{i=1}^{n}\left(p_{i}-\sigma\right)^{2}}
$$

The efficiency is given by the above formula (1), where $P_{i}$ are the simulated values and $\mathrm{O}_{\mathrm{i}}$ are the observed values
[30]. Interpolated daily temperature data were systematically tested for each of the 3652 created models. In terms of topographical parameters, the estimation of continuous tn and tx surfaces was done using the elevation, slope, orientation, humps, depressions and landscape roughness. These parameters were found to be the ones that best predicted tn or tx distribution for any given day of our study period.

\subsection{Agroclimatic indices and the GFV phenological model}

For each year of the selected timeframe 5 agroclimatic indices were calculated by cumulating the daily interpolated tn and tx. These indices were later spatialized and amongst them we mention the number of heat stress and that of frost days, the mid-flowering, the mid-verraison and the theoretical grape maturity (i.e. day when berries' sugar concentration attains $200 \mathrm{~g} / \mathrm{L}$ ). The heat stress days are defined as the days where the weather stations' tx are equal or greater than $35^{\circ} \mathrm{C}$ (Apr to Sep), whereas the days that count as frost days are those with tn equal or inferior to $-1^{\circ} \mathrm{C}$ (Mar to Jun). 
The three indices related to the grapevine phenology were simulated for the Chardonnay and the Pinot noir varieties with the GFV (Grape Flowering Veraison) model developed by [31]. They were estimated through the summation of temperatures over $10^{\circ} \mathrm{C}$ (counting from the $60^{\text {th }}$ day of the year which is either the 29 of Feb. or the $1^{\text {st }}$ of Mar.). Since these two are very similar in terms of heat requirements their thresholds were averaged (Table 1), giving us a mean heat cumulation value of 1218 to attain mid-floraison, 2529 for the mid-véraison and 2990 for the theoretical maturity. The model was validated with observed phenological data and it was found to simulate the phenology occurrence dates very close to those measured on the field, indicating a mean error of 5 days for the mid-flowering and 7 days for mid-véraison and theoretical grape maturity respectively.

\section{Results and discussion}

\subsection{Temperature spatial accuracy evaluation}

The statistics relative to the $\mathrm{tn}$ and tx quality of spatialization are shown in table 1. The performance indices were calculated for all stations as well as for those found in the vineyard areas only. The modelling precision (after interpolation) of daily temperatures across Burgundy was in average of $0.89^{\circ} \mathrm{C}$ for tx and of $1.23^{\circ} \mathrm{C}$ for tn (RMSE). This means that any given pixel's value has an error attached to it of $\pm 0.89( \pm 1.23){ }^{\circ} \mathrm{C}$ for the tx (tn). The medians of efficiencies and $\mathrm{R}^{2}$ are $0.42(0.54)$ and 0.67

\begin{tabular}{|c|c|c|c|c|c|c|c|}
\hline \multicolumn{2}{|c|}{} & \multicolumn{3}{c|}{$\begin{array}{c}\text { Vineyard area } \\
\text { stations }\end{array}$} & \multicolumn{3}{c|}{ All stations } \\
\cline { 3 - 8 } & & $\mathbf{R}^{\mathbf{2}}$ & RMSE & EF & $\mathbf{R}^{\mathbf{2}}$ & RMSE & EF \\
\hline \multirow{2}{*}{ Tn } & mean & 0.67 & 0.94 & 0.36 & 0.64 & 1.23 & 0.39 \\
\hline \multirow{2}{*}{ Tx } & med & 0.73 & 0.86 & 0.45 & 0.67 & 1.17 & 0.42 \\
\hline \multirow{2}{*}{} & mean & 0.74 & 0.70 & 0.35 & 0.74 & 0.89 & 0.51 \\
\hline & med & 0.78 & 0.67 & 0.45 & 0.76 & 0.86 & 0.54 \\
\hline
\end{tabular}

(0.76) respectively, for tn (tx).

Table 1: The three statistical indicators $\left(\mathrm{R}^{2}-\right.$ determination coefficient, RMSE - Root Mean Square Error, EF - modelling efficiency) used for the estimation of the interpolation quality performance, applied to all stations as well as to those stations covering only the vineyard area.

The validation (LOOCV) of temperature interpolations within the vineyard area exhibit similar performances, but with a higher $\mathrm{R}^{2}$. This suggests that a higher stations' density in the vineyard area allows a more accurate interpolation of temperatures and also a more homogeneous landscape/climate context (Figure 1b).

\subsection{Phenology occurrence dates classification}

Spatializing the agroclimatic indices relative to the grapevine's phenology allowed us to establish the viticultural zoning of Burgundy's vineyards thermal potentialities. These three phenological indices were spatially estimated across the 9 subregions (74556 pixels) mentioned in the previous sections and temporally estimated across the 5 years' timeframe (2011-2015). Therefore, temperature variability was assessed for both its spatial effect (terroir) and temporal effect (vintage). The 74556 pixels were later classified at regular intervals in 6 groups which were assigned to each of the three phenological indices: "very early" (red), "early" (orange), "intermediate" (yellow), "late" (green), "very late" (blue) and "variable" (Figure 2).

The pixels with a small DOY (day of year counting from Mar 1st) value were classed as "very early", while those having a high DOY value were classed as "very late". For the "variable" class, the interannual standard deviation (sd) was calculated for every pixel. If sd $>1$ then it means that the pixel value is very variable from one year to the next. In order to map these classes, the DOY values of each year were averaged for the 2011-2015 period (Figure 2 ). The same principle was applied to the heat stress and the frost (not shown in this paper) days with their occurrence being classed as "very rare", "rare", "intermediate", "frequent" and "very frequent".

\subsection{The theoretical grape maturity zoning}

Thermal variations in Burgundy have allowed for a classification of the theoretical grape maturity $(200 \mathrm{~g} / \mathrm{L}$ of sugar concentration) occurrence dates, with the 6 derived classes being detailed in table 2 . The values illustrated are those of the number of mean days per class and per year. Classes vary from "very early" (red) to "very late" (blue) and they represent smaller or larger groups of pixels, depending on how they were classified based on their maturity value. Interclass differences can be observed, with

\begin{tabular}{|c|c|c|c|c|c|c|c|}
\hline & Years & $\begin{array}{l}\text { Very } \\
\text { early }\end{array}$ & Early & Interm. & Late & $\begin{array}{l}\text { Very } \\
\text { late }\end{array}$ & Var \\
\hline \multirow{5}{*}{ 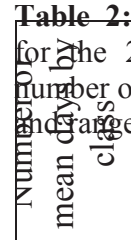 } & & 238 & 244 & 251 & 257 & 265 & 254 \\
\hline & & 241 & 248 & 255 & 262 & 269 & 263 \\
\hline & $20013^{v e}$ & 254 & 261 & 269 & 275 & 284 & 283 \\
\hline & 2014 & 243 & 249 & 257 & 262 & 270 & 263 \\
\hline & 2015 & 232 & 238 & 246 & 253 & 261 & 243 \\
\hline
\end{tabular}




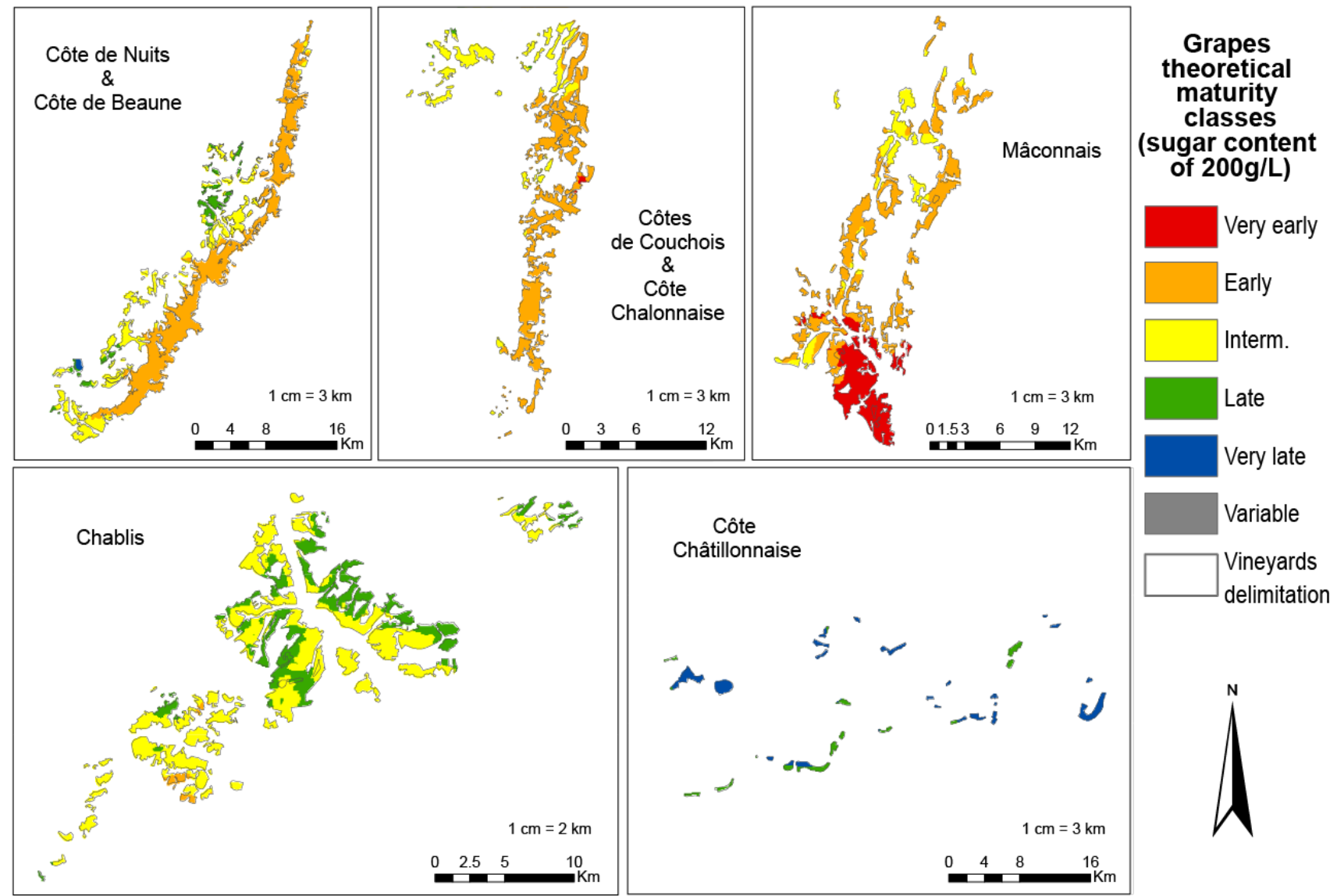

Figure 2: Spatialisation of "theoretical maturity" precocity classes for the Pinot noir and the Chardonnay varieties across the 9 subregions of Burgundy, based on the yearly cumulative temperatures of 2011-2015.

a gap ranging from 34 to 39 days (depending on year) between the earliest class and the latest. We notice that predicted theoretical maturity occurrence dates mirrors closely the field reality, the $200 \mathrm{~g} / \mathrm{L}$ sugar concentration being attained around the end of August (depending on year) which is very close to the harvest date in Burgundy (beginning of September, again depending on year). As mentioned above, table 2 provides only the average values of each class, but an intraclass variation has been equally observed. Each class is defined by an interval with a minimum and a maximum value, meaning that among the pixels of the same class there will still be a difference, although not as large as that between pixels belonging to different classes. Table 2 has been spatialized and the maturity classes can be observed in figure 2 for each of the subregions. $28 \%$ of the Mâconnais subregion has been classified as "very early", while Côte de Nuits, Côte de Beaune and Côte Chalonnaise have their largest area classified as "early" (97\%, 82\% et $83 \%$ respectively). Hautes Côtes de Nuits (56\%), Hautes Côtes de Beaune (76\%), Côtes du Couchois (97\%) and Chablis (66\%) are mainly classed as "intermediate", while Côte
Châtillonnaise is the only one considered as "very late". Furthermore, Côte de Nuits, Côte de Beaune and Côte Chalonnaise, where high added value wines are produced, exhibit limited variations in theoretical maturity timing despite a substantial South-North gradient. Finally, we would like to highlight that no zone of our study area has identified as "variable", meaning that the grape theoretical maturity remains consistent throughout the years indicating that the classification used in the zoning of thermic potentialities is particularly robust.

\subsection{Other phenological stages and thermal risks}

The mid-flowering and mid-véraison simulated phenological stages exhibit a similar pattern as that of the theoretical ripening (results not shown in this paper).

The climate risks associated to minimum and maximum temperatures that were estimated for this study were the number of heat stress days and that of frost days. The later exhibits a greater risk frequency in Chablis and the 
Châtillonnais, two subregions known for their higher predisposition to spring frost in comparison to others in Burgundy [32]. The spatial zoning of the number of heat stress days allowed us to identify winegrowing areas where the vine's thermal stress is more likely to occur during the summer period The days with temperatures equal or higher than $35^{\circ} \mathrm{C}$ are particularly frequent in the subregions of Chablis, the Châtillonnais and a small part of the Mâconnais which were classified as having an "intermediate" and "elevated" heat stress risk. All the other subregions are either classified with a "very rare" (up to 5 heat stress days/year) or a "rare" number of heat stress days. Among these we mention the Côte de Nuits and Hautes Côtes de Nuits, Côte de Beaune and Hautes Côtes de Beaune, as well as the Mâconnais.

\section{Conclusion}

Burgundy's agroclimatic potentialities have been analyzed, classified and spatialized. By using minimum and maximum temperature cumulations as well as a phenology simulation model, we were able to individually characterize Burgundy's main producing winegrowing subregions based on their thermic stress risk and their theoretical grape maturity ( $200 \mathrm{~g} / \mathrm{L}$ sugar concentration). Grape maturity was used as a proxy in order to estimate the influence of thermal regimes on the vines' different developmental stages and it provided us with clues as to the distribution of the different estimated precocity classes as well as their associated surfaces. Furthermore, local topography was integrated to this approach to further highlight the "mosaic" nature of Burgundy's terroirs. Although climate and topography are proved to be factors that limit the geography of grapevines, they are also the ones that give wine its typicality and authenticity [6], which is what the concept of "climats" is all about. This kind of climate spatial zoning provided us with a clear scientific basis of Burgundy's diversity in climate conditions and helped delineate the climate viticultural potential of each subregion. To our knowledge, this unique approach was used to serve a viticultural purpose only once before, when it was applied to the Bordeaux wine region $[12,13]$. Considering Burgundy's advancement in phenological dates due to recent climate changes [33], this kind of tool will give us a better understanding of the current terroir resilience and help us increase its adaptive capacity to climate change by offering a way to identify the appropriate strategies that will respond both to the environmental circumstances and the winemaker's needs.

\section{Acknowledgements:}

The authors would like to thank Météo-France, BIVB and Chambre Régional d'Agriculture de la Bourgogne for sharing their climate data and the Syndicat des Bourgogne for their financial support.

\section{References}

[1] J., Gladstones, 1992: Viticulture and Environment, Winetitles, Adelaide, $310 \mathrm{p}$.

[2] G.V., Jones, M.A., White, O.R., Cooper, K., Storchmann, 2005: Climate Change and Global Wine Quality. Climatic Change, 73, 319-343.

[3] C., van Leeuwen, P., Friant, X., Chone, O., Tregoat, S., Koundouras, et D., Dubourdieu, 2004: Influence of climate, soil, and cultivar on terroir. American Journal of Enology and Viticulture, 55(3): 207-217.

[4] D., Blanco-Ward, J.M., Garcia-Queijeiro et G.V., Jones, 2007: Spatial climate variability and viticulture in the Mino River Valley of Spain, Vitis $46,63-70$.

[5] A., Carbonneau, 2003: Ecophysiologie de la vigne et terroir, Terroir, Zonazione Viticol-tura, Piacenza, Italy (Phytoline: Piacenza).

[6] M.A., Amerine and A.J., Winkler, 1944: Composition and quality of musts and wines of California grapes, Hilgardia, 15, $n^{\circ} 6$.

[7] B., Bois, 2007: Cartographie agroclimatique à mésoéchelle : méthodologie et application à la variabilité spatiale du climat en Gironde viticole. Conséquences pour le développement de la vigne et la maturation du raisin. Thèse de Doctorat, Université de Bordeaux II.

[8] G.V., Jones, M, Moriondo, B, Bois, A., Hall, A., Duff, 2009: Analysis of the spatial climate structure in viticulture regions worldwide. Le Bulletin de l'OIV 82(944,945,946): 507-518.

[9] J., Tonietto, A., Carbonneau, 2004: A multicriteria climatic classification system for grape-growing regions worldwide. Agric. Forest Meteorol. 124, 8197.

[10] H., Quénol, 2014: Changement climatique et terroirs viticoles. Lavoisier, Paris, 444 pages.

[11] A., Jacquet and R., Morlat, 1998: Caractérisation de la variabilité climatique des terroirs viticoles en val 
de Loire. Influence du paysage et des facteurs physiques du milieu. Agronomie, 17(9/10): 465480.

[12] B., Bois, C., van Leeuwen, P., Pieri, J.P., Gaudillère, E., Saur, D., Joly, L., Wald, D., Grimal, 2008: Viticultural agroclimatic cartography and zoning at mesoscale level using terrain information, remotely sensed data and weather station measurements. Case study of Bordeaux winegrowing area, in: Proceedings of the VIIth International terroir Congress, pp. 455-462.

[13] B., Bois, C., van Leeuwen, 2008: Variabilité climatique dans la zone de production des vins de Bordeaux. Terroirs viticoles, ENITA Bordeaux, 4550 .

[14] D.D., Cichi, D.C., Costea, I., Olteanu, 2007: Effets des champs climatiques sur la vigne cultivée au sud de la Roumanie, Université de Craiova, Faculté d'Horticulture, Craiova.

[15] C., Bonnefoy, 2013: Observation et modélisation spatiale de la température dans les terroirs viticoles du Val de Loire dans le contexte du changement climatique, Thèse de doctorat, Université de Rennes 2.

[16] I., Chuine, P., Yiou, N., Viovy, B., Seguin, V., Daux and E., Le Roy Ladurie, 2004: Grape ripening as a past climate indicator, Nature, 432, 289-290.

[17] F., Spanik, B., Siska, and M., Galik, 2004: Changes in the phenology of grapevines (Vitis vinifera) as influenced by climate change impacts in Slovakia. Meteorol. Casopis 4:179-182.

[18] L.B., Webb, P.H., Whetton, et E.W.R., Barlow, 2008: Modelled impact of future climate change on the phenology of winegrapes in Australia. Aust. J. Grape Wine Res. 13:165-175.

[19] G., Seguin, 1970: Les sols de vignobles du HautMédoc. Influence sur l'alimentation en eau de la vigne et sur la maturation du raisin. Thèse de Doctorat d'Etat, 141 p., Faculté des Sciences, Université de Bordeaux.

[20] E., Lebon, A., Pellegrino, F., Tardieu, et J., Lecoeur, 2004: Shoot development in grapevine (Vitis vinifera) is affected by the modular branching pattern of the stem and intra- and inter-shoot trophic competition. Annals of Botany, 93(3): 263-274
[21] D., Joly, 2009: LISDQS: logiciel d'interpolation statistique de données quantitatives et spatiales. http://thema.univ-fcomte.fr/LISDQS-un-nouveau$\underline{\text { logiciel-d. }}$

[22] R., Geiger, 1969: Topoclimates, in World Survey of Climatology.

[23] G., Guyot, 1997: Climatologie de l'environnement, in Masson.

[24] D., Joly, T., Brossard, H., Cardot, J., Cavailhes, M., Hilal, P., Wavresky, 2010: Les types de climats en France, une construction spatiale. Cybergeo : European Journal of Geography: 21p.

[25] M., Madelin, B., Bois, J.P., Chabin, 2010: Modification des conditions de maturation du raisin en Bourgogne viticole liée au réchauffement climatique. EchoGéo 14 : 11p. URL: http://echogeo.revues.org/12176

[26] J.P., Chabin, M., Madelin, C., Bonnefoy, 2007: Les vignobles beaunois face au réchauffement climatique. Actes du colloque "Réchauffement climatique, quels impacts probables sur les vignobles?", Dijon, 28-30 Mars : 13p.

[27] European Environment Agency, 2016. Corine Land Cover (CLC) 2012, Version 18.5.1. URL: http://land.copernicus.eu/pan-european/corine-landcover/clc-2012/view

[28] I., Odeha, A., McBratney, D., Chittleborough, 1994: Spatial prediction of soil properties from landform attributes derived from a digital elevation model, Geoderma.

[29] T., Hengl, G.B.M., Heuvelink, D.G., Rossiter, 2007: About regression-kriging: from equations to case studies. Comput. Geosci. 33, 1301e1315.

[30] D.G., Mayer, and D.G., Butler, 1993: Statistical validation. Ecol. Model., 68: 21-32.

[31] A.K., Parker, I., Garcia de Cortazar-Atauri, C., van Leeuwen, et I., Chuine, 2011: A general phenological model to characterise the timing of flowering and veraison of Vitis vinifera L.Aust. J. Grape Wine Res., $17, \mathrm{n}^{\circ} 2,206-216$.

[32] J.F., Bazin, 2015. Le vin de Bourgogne. Dunod. $264 p$. 
[33] C., Cuccia, 2013: Impact du changement climatique sur la phénologie du Pinot noir en Bourgogne, Thèse de doctorat, Université de Bourgogne. 